\title{
Optimization of intrinsic layer thickness, dopant layer thickness and concentration for a-SiC/a-SiGe multilayer solar cell efficiency performance using Silvaco software
}

\author{
Wong Wei Yuan ${ }^{1}$, Mohd Natashah Norizan ${ }^{1,2,3,}$, Ili Salwani Mohamad ${ }^{1,2,3}$, Nurnaeimah Jamalullail ${ }^{1,2}$, and Nor Hidayah \\ Saad $^{1}$ \\ ${ }^{1}$ School of Microelectronic Engineering, Universiti Malaysia Perlis, Pauh Putra Campus, 02600 Arau, Perlis, Malaysia. \\ ${ }^{2}$ Centre of Excellence Geopolymer and Green Technology (CeGeoGTech), Universiti Malaysia Perlis, Perlis, Malaysia. \\ ${ }^{3}$ Advanced Multi-Disciplinary MEMS-Based Integrated NCER Centre of Excellence (AMBIENCE), Universiti Malaysia Perlis, Perlis, \\ Malaysia.
}

\begin{abstract}
Solar cell is expanding as green renewable alternative to conventional fossil fuel electricity generation, but compared to other land-used electrical generators, it is a comparative beginner. Many applications covered by solar cells starting from low power mobile devices, terrestrial, satellites and many more. To date, the highest efficiency solar cell is given by GaAs based multilayer solar cell. However, this material is very expensive in fabrication and material costs compared to silicon which is cheaper due to the abundance of supply. Thus, this research is devoted to develop multilayer solar cell by combining two different layers of P-I-N structures with silicon carbide and silicon germanium. This research focused on optimising the intrinsic layer thickness, p-doped layer thickness and concentration, n-doped layer thickness and concentration in achieving the highest efficiency. As a result, both single layer a-SiC and a-SiGe showed positive efficiency improvement with the record of $27.19 \%$ and $9.07 \%$ respectively via parametric optimization. The optimized parameters is then applied on both SiC and SiGe P-I-N layers and resulted the convincing efficiency of $33.80 \%$.
\end{abstract}

\section{Introduction}

In modelling multilayer Silicon ( $\mathrm{Si}$ ) solar cell using silicon carbide ( $\mathrm{SiC}$ ) based solar cell layer, amorphous silicon (a-Si) alloy is considered as an important material of the multilayer solar cell based on many researches [14]. a-Si alloy is a material that used to reduce the cost of solar cells in the future [5,6]. The material is easy to dope compared to crystalline $\mathrm{Si}$, hence the energy used in doping process can be saved $[7,8]$. By combining a-Si and intrinsic layer formation, it has high optical absorption coefficient over the wavelength of solar spectrum that enable to fabricate thin film solar cell that can fully absorb the incoming light in its very thin thickness layer [9]. Hence, it can be used to design low cost thin film solar cell [10].

\subsection{P-I-N solar cell structure}

In an a-Si alloy, the alloy needed to be hydrogenated because of amorphous silicon has different bond angles and bond length in single units of a-Si cell compared to crystalline Si [11]. Thus, a-Si has possibility to form dangling bond defect, which the certain bond will be totally missing $\mathrm{Si}$ atom. Therefore, hydrogen dilution is needed to prevent loss bonding of neighbouring $\mathrm{Si}$ atoms.

\footnotetext{
*Corresponding author: mohdnatashah@unimap.edu.my
}

Figure 1 shows the structure of P-I-N solar cell with its doping density. The top doping is p-layer while the bottom doping is n-layer of the solar cell. Two layers of Indium Tin Oxide (ITO) which is colourless and transparent are coated on the bottom and top of the solar cell to act as a contact.

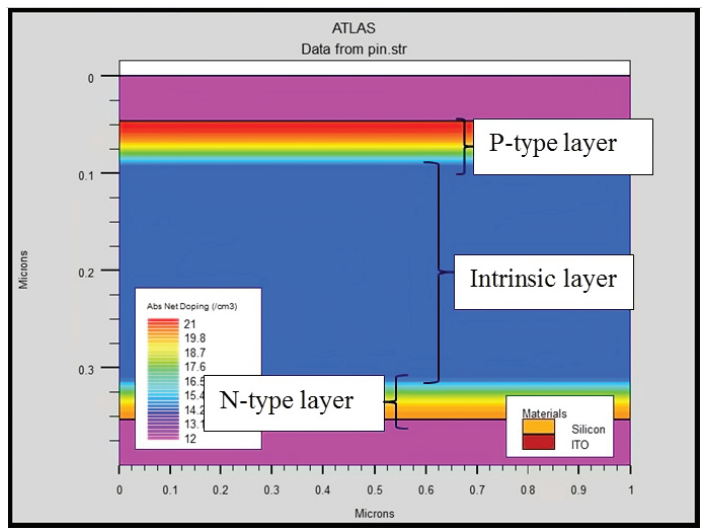

Fig. 1. Structure of P-I-N Solar Cell with its doping density.

Combination of a-Si and intrinsic layer produced an a-Si layer with low dopant concentration which is important to form P-I-N structure of the solar cell. This 
design has high optical absorption coefficient over the wavelength of solar spectrum that enable to fabricate thin film solar cell that can fully absorb the incoming light in its very thin thickness layer [12]. The band gap energy of this combination of materials is high enough to cover relatively more high light intensity in solar spectrum compared to crystalline Si [13]. The intrinsic layer also has much stronger internal electric field to separate electrons and holes efficiently, which avoid additional energy losses [14].

\subsection{Operation of $\mathrm{P}-\mathrm{I}-\mathrm{N}$ solar cell}

The operation of solar cell consists of two main steps. In the first step, photons are striking on the Si layer surface and absorbed at these layers to create free electrons and holes[15]. The energy of the photon must higher or equal to the band gap energy of these $\mathrm{Si}$ layers to ensure absorption of the photon. When the energy of photon is equal to the energy of the band gap, single electron hole pair will be generated without loss of energy. When the energy of photon is larger than the energy of the band gap, the excess energy of photon minus the band gap energy $\left(E_{p h}-E_{g}\right)$ will rapidly transform into heat after generation of the single electron hole pair. When the energy of photon is lesser than the band gap energy, the photon will either be reflected or absorbed elsewhere [16]. This low energy of photons will be absorbed due to impurities or defect introduced within the gap.

In the second step, these electron hole pairs have to be isolated by guiding the electron to one side and the holes to the other side of the solar cell device [16]. Thus, an internal electric field created by intrinsic layer can separate them by a potential difference as shown in Figure 2. Figure 2 is not only an energy band diagram that shows the band gap energy of p-doped, n-doped layer and intrinsic layer of silicon, but it shows the larger separation of p-doped layer energy band and n-doped layer energy band which can separate electron at conduction band of $\mathrm{n}$-doped layer recombination to valence band of p-doped layer. Hence, majority carriers of p-doped layer and n-doped layer which were electrons and holes that have opposite electric charges will move in opposite directions within an electric field to create a voltage for external use [16].

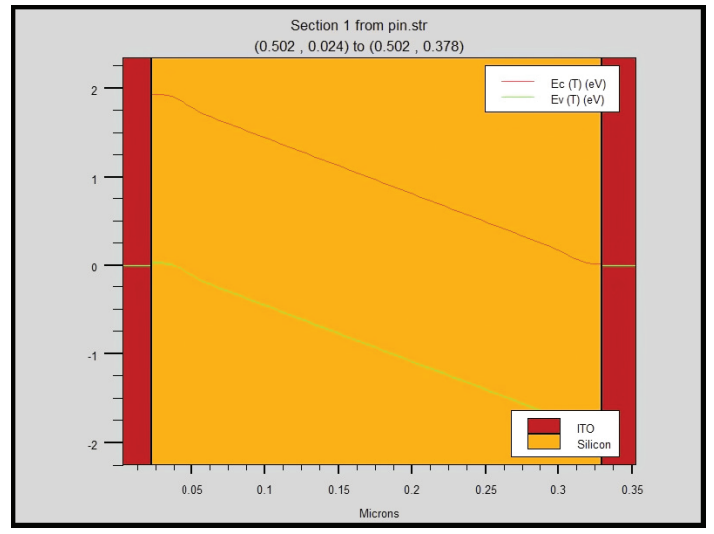

Fig. 2. Energy band diagram in P-I-N solar cell.

\subsection{Design of P-I-N multilayer SiC solar cell}

In all layers of multilayer silicon alloy solar cell shown in Figure 3, p-doped a-H is hydrogenated amorphous material that doped with a p-type dopant, an intrinsic layer of $\mathrm{a}-\mathrm{H}$ is hydrogenated amorphous material that doped lightly with n-type dopant, and $\mathrm{N}$-doped a-H is hydrogenated amorphous material that doped with n-type dopant.

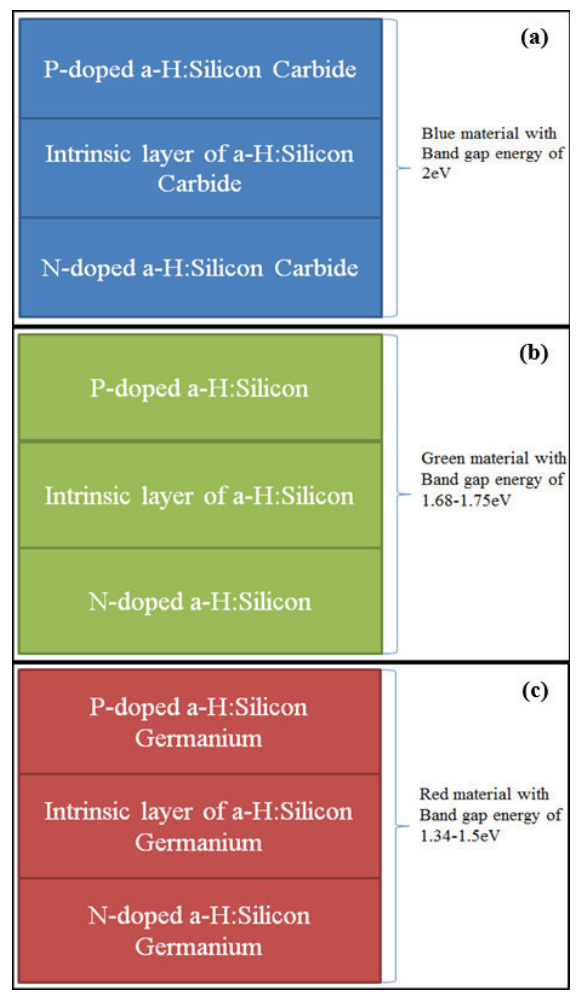

Fig. 3. (a) Top, (b) middle and (c) bottom layer of multilayer $\mathrm{Si}$ alloy solar cell.

The material for top layer is silicon carbide, middle layer is silicon, and bottom layer is silicon germanium. The blue material with band gap energy of $2 \mathrm{eV}$ is able to absorb short wavelength with high light intensity which will not only contribute high voltage but also high current with its high light intensity [17]. Secondly, green material (a-Si) with energy band gap in between $1.68 \mathrm{eV}$ and $1.75 \mathrm{eV}$ is prefect material to be the second layer only if third layer that absorbs red photon exist.

\section{Details of the simulated solar cell}

In order to simulate a-SiC/SiGe multilayer solar cells, a commercial simulation software application, Silvaco TCAD was used. The program computes the generating functions of electron-hole pairs from the optical parameters of each layer [18-20]. In this study, optical constants have been used, which are the refractive index and the extinction coefficient as functions of the wavelength for the layers used in the solar cell, of all individual layers as input optical parameters in the reference. 


\subsection{Baseline parameter of single layer solar cell}

Since amorphous silicon carbide and amorphous silicon germanium are amorphous silicon alloy, amorphous silicon is the most basic material that can be alloyed with other elements such as carbon (C) and germanium (Ge) [5]. Thus, baseline values of the parameters used to optimize the efficiency of every layer solar cell can be referred from the parameter values of efficiency optimized amorphous silicon single layer solar cell. The parameters of interest are intrinsic layer thickness, pdoped layer thickness, n-doped layer thickness, p-doped layer concentration and n-doped layer concentration. Other than that, the parameters that are constant were set by simulating to default value, only one parameter can be changed to find the maximum efficiency in order to optimize this single layer solar cell efficiency.

In Table 1, values in a row no. 1 until row no. 5 are the increment of $\mathrm{P}$ type dopant concentration to give the increment result of the efficiency of P-I-N solar cell. The values of n-type dopant were increased as shown by the values in row no. 5 until row no. 8 until a maximum efficiency was achieved as shown in row no. 7 which is 4.42 percent. This showed that increment of p-type and n-types dopant concentration will increase the efficiency, but depend on the increment of its opposite layer dopant concentration.

For an example, when p-type concentration increases until a value of efficiency stagnate, increment of its opposite type layer dopant concentration will actually increase the efficiency of P-I-N solar cell. Therefore, increment of opposite type layer dopant concentration after maximizing its dopant concentration will increase the efficiency. However, row of no. 9 explained that the efficiency does not increase but decrease to 4.21 percent. This proven that the maximum efficiency from manipulation of $\mathrm{P}$ type and $\mathrm{N}$ type dopant concentration is 4.42 percent. In conclusion, the baseline value for $\mathrm{P}$ type and $\mathrm{N}$ type dopant concentration were $1 \mathrm{e} 21$ and $1 \mathrm{e} 21$ respectively.

Table 1. Efficiency optimization with p-doped layer and ndoped layer.

\begin{tabular}{|c|c|c|c|}
\hline No. & $\begin{array}{c}\text { P- Concentration } \\
\left(\mathbf{c m}^{-3}\right)\end{array}$ & $\begin{array}{c}\text { N- Concentration } \\
\left(\mathbf{c m}^{-3}\right)\end{array}$ & $\begin{array}{c}\text { Efficiency } \\
(\mathbf{\%})\end{array}$ \\
\hline 1 & $4 \times 10^{17}$ & $1 \times 10^{18}$ & 4.134 \\
\hline 2 & $1 \times 10^{18}$ & $1 \times 10^{18}$ & 4.213 \\
\hline 3 & $1 \times 10^{19}$ & $1 \times 10^{18}$ & 4.33 \\
\hline 4 & $1 \times 10^{20}$ & $1 \times 10^{18}$ & 4.35 \\
\hline 5 & $1 \times 10^{21}$ & $1 \times 10^{18}$ & 4.35 \\
\hline 6 & $1 \times 10^{21}$ & $1 \times 10^{19}$ & 4.36 \\
\hline 7 & $1 \times 10^{21}$ & $1 \times 10^{20}$ & 4.38 \\
\hline 8 & $1 \times 10^{21}$ & $1 \times 10^{21}$ & 4.42 \\
\hline 9 & $1 \times 10^{22}$ & $1 \times 10^{21}$ & 4.21 \\
\hline
\end{tabular}

For the intrinsic layer, the thickness can be changed in between 0.15 micron and 0.3 micron [15]. In Table 2 , the thickness of intrinsic layer is increased to 2 microns to achieve efficiency of $10.05 \%$, otherwise the efficiency is lower than $10.05 \%$. Therefore, the baseline value for the intrinsic layer thickness is chosed to be $2 \mu \mathrm{m}$.
Table 2. Efficiency optimization with intrinsic layer thickness.

\begin{tabular}{|c|c|c|}
\hline No. & Thickness $(\boldsymbol{\mu m})$ & Efficiency $(\%)$ \\
\hline 1 & 0.25 & 4.36 \\
\hline 2 & 0.3 & 4.42 \\
\hline 3 & 0.35 & 4.826 \\
\hline 4 & 0.4 & 5.16 \\
\hline 5 & 0.5 & 5.96 \\
\hline 6 & 0.6 & 6.63 \\
\hline 7 & 0.7 & 7.17 \\
\hline 8 & 0.8 & 7.63 \\
\hline 9 & 0.9 & 7.65 \\
\hline 10 & 1 & 8.51 \\
\hline 11 & 1.5 & 9.42 \\
\hline 12 & 2 & 10.05 \\
\hline 13 & 2.5 & 10.005 \\
\hline
\end{tabular}

The default values of $n$-doped layer and p-doped layer thickness were not changed since the efficiency of solar cell will be decreased when the thickness were changed as shown in Table 3 and 4. Therefore, baseline values of $\mathrm{n}$-doped layer and $\mathrm{p}$-doped layer thickness were 0.05 microns.

Table 3. Efficiency optimization with p-doped layer thickness.

\begin{tabular}{|c|c|c|}
\hline No. & Thickness $(\boldsymbol{\mu m})$ & Efficiency (\%) \\
\hline 1 & 0.06 & 9.76 \\
\hline 2 & 0.05 & 10.05 \\
\hline 3 & 0.04 & 10.007 \\
\hline
\end{tabular}

Table 4. Efficiency optimization with n-doped layer thickness.

\begin{tabular}{|c|c|c|}
\hline No. & Thickness $(\boldsymbol{\mu m})$ & Efficiency (\%) \\
\hline 1 & 0.06 & 10.003 \\
\hline 2 & 0.05 & 10.05 \\
\hline 3 & 0.04 & 10.045 \\
\hline
\end{tabular}

\subsection{Simulation of a-SiC/a-SiGe multilayer solar cells}

Figure 4 (a) shows the baseline structure with the meshing, thickness of the material region and electrodes; doping statement in Figure 4 (b) specified the doping concentration in each region. The meshing used in $\mathrm{x}$-axis is spaced every 0.2 micron to 1 micron and automatically spaced in the y-axis. Meshing statement "qty.m" and "qtx.m" is used to declare the structure in that dimension of a tunnel junction.

Material thickness of each region is listed in Figure 4 (b) using "y.min" and "y.max". The materials of each region was listed inside the coding using "mat". The tunnel junction is deposited in between a-SiC top layer solar cell and a-SiGe bottom layer solar cell. The material used for tunnel junction is $\mathrm{SiC}$, which is the same material used in the top layer of solar cell. The thickness and the doping concentration of p-type layer and n-type layer are both 0.05 micron and $1 \times 10^{15} \mathrm{~cm}^{-3}$ respectively. 


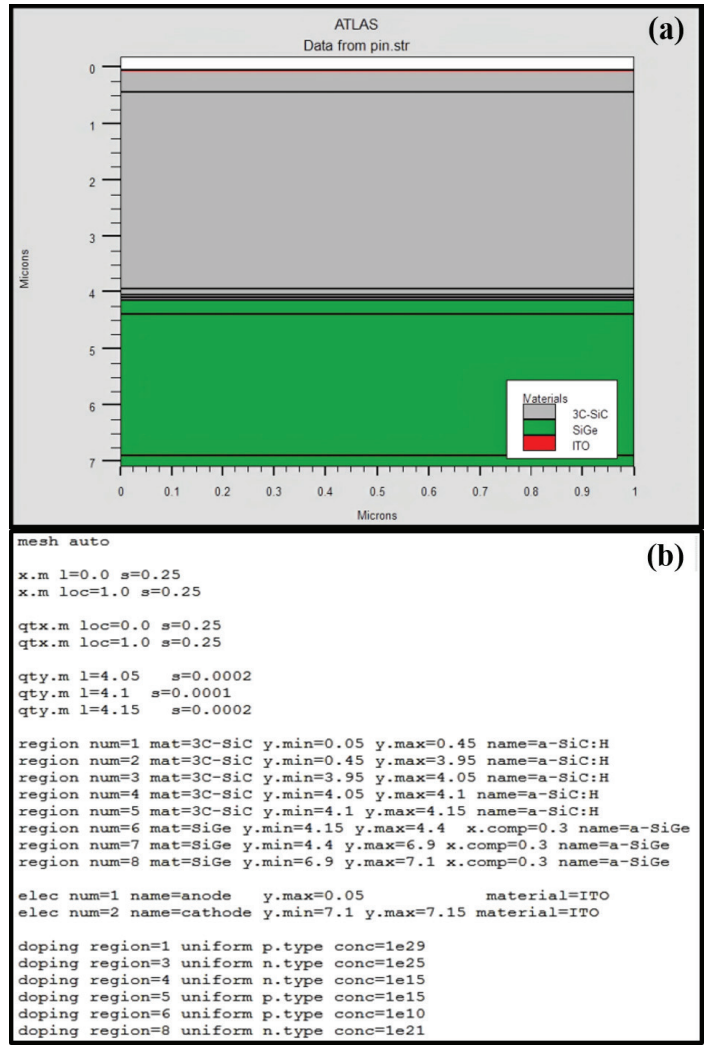

Fig. 4. (a) Baseline structure of multilayer solar cell and (b) coding of multilayer solar cell structure specification group statements.

\section{Results and discussions}

The optimized results shown in Table 5 were obtained by doing a parametric study on every parameter. Parameters that effect the efficiency increment of a-SiC single layer solar cell obtained from this study were ntype dopant concentration and intrinsic layer thickness while for a-SiGe single layer solar cell is $\mathrm{n}$-type layer thickness.

Table 5. Optimized results for a-SiC and a-SiGe single layer solar cell.

\begin{tabular}{|c|c|c|}
\hline Parameter & a-SiC & a-SiGe \\
\hline p-type dopant concentration $\left(\mathrm{cm}^{-3}\right)$ & $1 \times 10^{29}$ & $1 \times 10^{10}$ \\
\hline n-type dopant concentration $\left(\mathrm{cm}^{-3}\right)$ & $1 \times 10^{25}$ & $1 \times 10^{21}$ \\
\hline n-type layer thickness (micron) & 0.1 & 0.2 \\
\hline p-type layer thickness $($ micron$)$ & 0.4 & 0.25 \\
\hline Intrinsic layer thickness $(\mu \mathrm{m})$ & 3.5 & 2.5 \\
\hline
\end{tabular}

In Figure 5 (a) and (c), open-circuit voltage $\left(\mathrm{V}_{\mathrm{oc}}\right)$ were $1.85 \mathrm{~V}$ same for both (a-SiC and $\mathrm{SiC} / \mathrm{a}-\mathrm{SiGe})$ and at this time there were no current flows through the circuit and it is the maximum voltage that the solar cell can generate. At Short-circuit current $\left(\mathrm{I}_{\mathrm{sc}}\right) 1.59 \mathrm{~mA}$ (a$\mathrm{SiC})$ and $1.97 \mathrm{~mA}(\mathrm{SiC} / \mathrm{a}-\mathrm{SiGe})$, this was where current flow through the circuit when the electrodes are shortcircuited. The $\mathrm{I}_{\mathrm{sc}}$ of a solar cell depends on the photon flux density incident on the solar cell, which is determined by the spectrum of incident light.
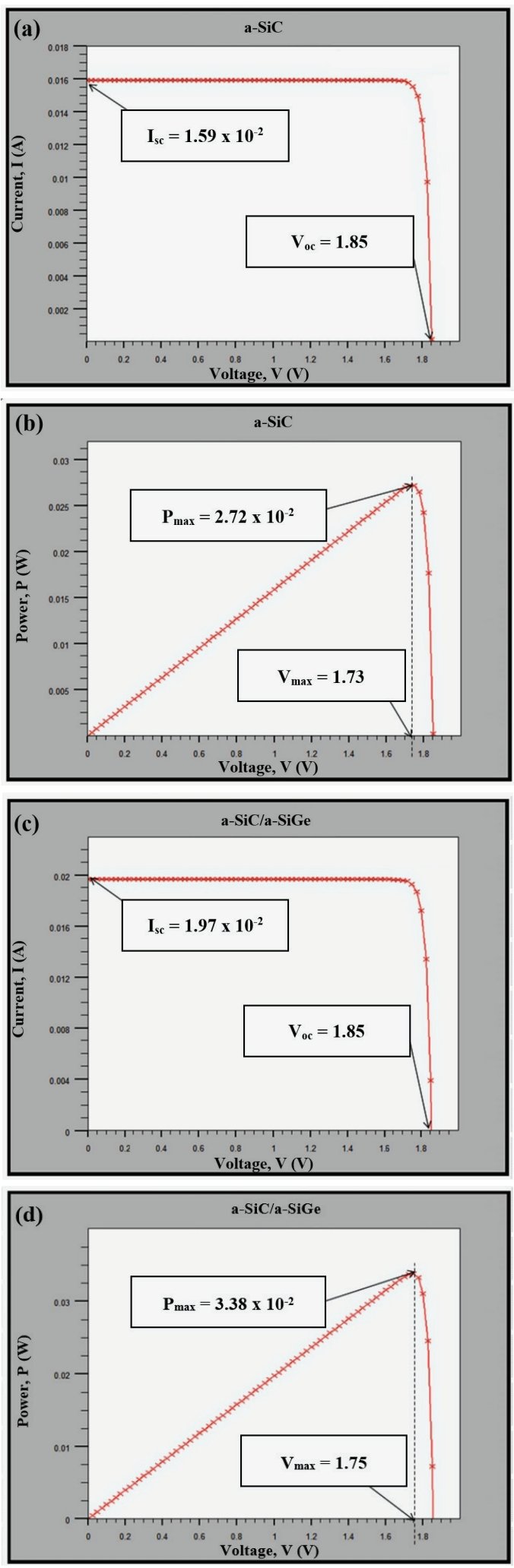

Fig. 5. Characteristic curves (a) $\mathrm{I}-\mathrm{V}$ and (b) $\mathrm{P}-\mathrm{V}$ of a-SiC solar cell and (c) I-V and (d) P-V of a-SiC/a-SiGe solar cell. 
In Figure 5 (b) and (d), maximum power output $\left(\mathrm{P}_{\max }\right)$ also known as the maximum power point is 2.72 $\mathrm{mW}$ for an $\mathrm{a}-\mathrm{SiC}$ and $3.38 \mathrm{~mW}$ for a SiC/a-SiGe solar cell as shown at the peak of the P-V curve. $\mathrm{P}_{\max }$ is a key parameter since solar cells are used to produce electrical energy. Solar cell produces no power when it is in an open-circuit or short-circuit state. The maximum voltage $\left(\mathrm{V}_{\max }\right)$ is $1.73 \mathrm{~V}(\mathrm{a}-\mathrm{SiC})$ and $1.75 \mathrm{~V}(\mathrm{SiC} / \mathrm{a}-\mathrm{SiGe})$ when a solar cell reaches it's maximum power. The maximum current $\left(\mathrm{I}_{\max }\right)$ of the solar cell is $1.57 \mathrm{~mA}(\mathrm{a}-\mathrm{SiC})$ and $1.93 \mathrm{~mA}(\mathrm{SiC} / \mathrm{a}-\mathrm{SiGe})$ calculated using the following formula $\mathrm{I}_{\max }=\mathrm{P}_{\max } / \mathrm{V}_{\max }$.

Table 6. Optimized simulation results of a-SiC single layer solar cell and a-SiC/a-SiGe multilayer solar cell.

\begin{tabular}{|c|c|c|}
\hline Photovoltaic Parameter & a-SiC & a-SiC/a-SiGe \\
\hline Short Circuit Current, $I_{s c}(\mathrm{~mA})$ & 1.59 & 1.97 \\
\hline Open Circuit Voltage, $V_{o c}(\mathrm{~V})$ & 1.85 & 1.85 \\
\hline Maximum Voltage, $\mathrm{V}_{\max }(\mathrm{V})$ & 1.73 & 1.75 \\
\hline Maximum Current, $\mathrm{I}_{\max }(\mathrm{mA})$ & 1.57 & 1.93 \\
\hline Fill Factor, $\mathrm{FF}$ & 0.92 & 0.93 \\
\hline Maximum Power, $\mathrm{P}_{\max }(\mathrm{mW})$ & 2.72 & 3.38 \\
\hline Input Power, $\mathrm{P}_{\text {in }}\left(\mathrm{kW} / \mathrm{m}^{2}\right)$ & 0.10 & 0.10 \\
\hline Efficiency $\eta(\%)$ & 27.20 & 33.80 \\
\hline
\end{tabular}

The simulated values such as $\mathrm{I}_{\mathrm{sc}}, \mathrm{V}_{\mathrm{oc}}, \mathrm{V}_{\max }, \mathrm{I}_{\max }, \mathrm{P}_{\max }$ were collected from Figure 5 and summarized in Table 6. Fill factor (FF) of $0.92(\mathrm{a}-\mathrm{SiC})$ and 0.93 (a-SiC/a$\mathrm{SiGe}$ ) were calculated by using the equation $\mathrm{FF}=\mathrm{P}_{\max } /\left(\mathrm{I}_{\mathrm{sc}} \times \mathrm{V}_{\mathrm{oc}}\right)$. The efficiency of optimized a-SiC/aSiGe multilayer solar cell is $33.8 \%$, while the efficiency of optimized a-SiC single layer solar cell is $27.2 \%$ and this shows an improvement of $6.6 \%$

The n-type dopant concentration of $1 \times 10^{25} \mathrm{~cm}^{-3}$ is considered highly doped concentration. High n-doped concentration allowed more light to pass through the intrinsic layer to improve the open-circuit voltage and short-circuit. This result supported by A. Kosarian and P. Jelodarian in their research results which shown that high $\mathrm{n}$-doped concentration will increase open-circuit voltage and short-circuit current [21].

The intrinsic layer of $3.5 \mu \mathrm{m}$ play very important role to separate electrons and holes that was generated to prevent electron recombine back to holes at valence band. Thus, it improved a-SiC/a-SiGe multilayer solar cell from avoiding additional energy losses.

\section{Conclusions}

This work demonstrated the optimization of intrinsic layer thickness, dopant layer thickness and concentration for a-SiC/a-SiGe multilayer solar cell, which improved the efficiency performance. Efficiency of $33.8 \%$ of the double layers a-SiC/a-SiGe solar cell which improved $6.6 \%$ in efficiency from single layer a-SiC solar cell has been achieved through this research by optimization through parametric study. The results proved that correct material combination can contribute to the increment of solar cell efficiency when compared with the single layer a-SiC solar cell simulated with only $27.2 \%$ in efficiency.
The author would like to acknowledge the support from the Fundamental Research Grant Scheme (FRGS) Grant under a grant number of 9003-00339 and Research Acculturation Grant Scheme (RAGS) under a grant number of RAGS/1/2015/SG0/UNIMAP/03/3 from the Ministry of Higher Education (MoHE) Malaysia.

\section{References}

1. I. Afdi Yunaz, S. Miyajima, and M. Konagai, in 2010 35th IEEE Photovolt. Spec. Conf. (IEEE, 2010), pp. 000317-000322.

2. S. De Wolf, A. Descoeudres, Z. C. Holman, and C. Ballif, Green 2, 7 (2012).

3. Kyung Hoon Jun, Sung Won Kwon, and Koeng Su Lim, in Conf. Rec. Twenty-Eighth IEEE Photovolt. Spec. Conf. - 2000 (Cat. No.00CH37036) (IEEE, 2000), pp. 924-927.

4. J. Burdick and T. Glatfelter, Sol. Cells 18, 301 (1986).

5. I. A. Yunaz, A. Yamada, and M. Konagai, Jpn. J. Appl. Phys. 46, L1152 (2007).

6. M. A. Green, Prog. Photovoltaics Res. Appl. 9, 123 (2001).

7. J. Poortmans and V. Arkhipov, in Sol. Cells (2006), p. 471.

8. A. Scuto, M. Foti, C. Gerardi, A. Battaglia, and S. Lombardo, IEEE Int. Reliab. Phys. Symp. Proc. 2016-Septe, 3C31 (2016).

9. J. Zhu, Z. Yu, G. F. Burkhard, C.-M. Hsu, S. T. Connor, Y. Xu, Q. Wang, M. McGehee, S. Fan, and Y. Cui, Nano Lett. 9, 279 (2009).

10. S. Kim, J. W. Chung, H. Lee, J. Park, Y. Heo, and H. M. Lee, Sol. Energy Mater. Sol. Cells 119, 26 (2013).

11. W. G. J. H. M. Van Sark, in Thin Film. Nanostructures (2002), pp. 1-215.

12. X. Meng, G. Gomard, O. El Daif, E. Drouard, R. Orobtchouk, A. Kaminski, A. Fave, M. Lemiti, A. Abramov, P. Roca i Cabarrocas, and C. Seassal, Sol. Energy Mater. Sol. Cells 95, S32 (2011).

13. P. Sánchez, O. Lorenzo, A. Menéndez, J. L. Menéndez, D. Gomez, R. Pereiro, and B. Fernández, Int. J. Mol. Sci. 12, 2200 (2011).

14. L. Li, P. A. Salvador, and G. S. Rohrer, Nanoscale 6, 24 (2014).

15. S. M. Zahari, R. A. M. Osman, M. N. Norizan, I. S. Mohamad, A. Malini, and S. Taking, Appl. Mech. Mater., pp. 1182-1186, 2015.

16. A. Shah, Thin-Film Silicon Solar Cells (EPFL Press, 2010).

17. A. A. Boussettine, Y. Belhadji, and A. Benmansour, Energy Procedia 18, 693 (2012).

18. Silvaco, ATLAS User's Manual (2016).

19. M. N. Norizan, S. M. Zahari, I. S. Mohamad, R. A. M. Osman, M. M. Shahimin, and S. A. Z. Murad, IOP Conf. Ser. Mater. Sci. Eng., 209, (2017). 
20. S. M. Zahari, M. N. Norizan, I. S. Mohamad, R. A. M. Osman, and S. Taking, AIP Conf. Proc., 1660, May, (2015).

21. A. Kosarian and P. Jelodarian, in 2011 Third Int. Conf. Comput. Intell. Model. Simul. pp. 417-422. (IEEE, 2011), 